\title{
GERMINAÇÃO E VIGOR DE SEMENTES DE Myracrodruon urundeuva ALLEMÃO EM DIFERENTES SUBSTRATOS E TEMPERATURAS ${ }^{1}$
}

\author{
Roberta Sales Guedes², Edna Ursulino Alves³ ${ }^{3}$ Edilma Pereira Gonçalves ${ }^{4}$, \\ Pedro Nóbrega Quintas Colares ${ }^{5}$, Matheus Serrano de Medeiros ${ }^{6}$ e Jeandson Silva Viana ${ }^{4}$
}

\begin{abstract}
RESUMO - Myracrodruon urundeuva Allemão é uma espécie pertencente à família Anacardiaceae, cuja planta pode ser medicinal, ser usada na indústria de curtimento de couro, na arborização de ruas e praças. Dessa forma, objetivou-se, com esta pesquisa, determinar metodologias adequadas para a condução de testes de germinação e vigor de sementes de $M$. urundeuva. Foram utilizadas as temperaturas de 25 , 30 e $35^{\circ} \mathrm{C}$ constante e $20-30{ }^{\circ} \mathrm{C}$ alternada, juntamente com os substratos areia, vermiculita, bioplant ${ }^{\circledR}$, plantmax ${ }^{\circledR}$, entre e sobre papel mata-borrão e papel-toalha, organizado na forma de rolo. O delineamento experimental foi inteiramente ao acaso, em quatro repetições de 25 sementes. Foram analisadas as seguintes características: porcentagem e velocidade de germinação, primeira contagem de germinação e comprimento e massa seca de plântulas. A temperatura de $30^{\circ} \mathrm{C}$ e o substrato areia são indicados para a realização dos testes de germinação e vigor das sementes de M. urundeuva.
\end{abstract}

Palavras-chave: Aroeira, Sementes florestais, Planta medicinal e Análise de sementes.

\section{GERMINATION AND VIGOR OF Myracrodruon urundeuva ALLEMÃO SEEDS IN DIFFERENT SUBSTRATES AND TEMPERATURES}

\begin{abstract}
Myracrodruon urundeuva Allemão belongs to Anacardiaceae family, whose plants can be medicinal, it can be used in leather tanning industry, tree planting in urban areas because of its great mechanic resistance wood. Therefore, the objective of this work was to determine methodologies proper to conduction of tests of germination and vigor of M. urundeuva seeds. The temperatures utilized were 25,30 and $35^{\circ} \mathrm{C}$ (constant) and $20-30^{\circ} \mathrm{C}$ (alternate), together with the substrates sand, vermiculite, bioplant ${ }^{\circledR}$, plantmax $^{\circledR}$, blotting paper, with seeds upon the paper and between paper sheets and towel paper, in the form of paper rolls. The experimental design was completely randomized, with four replicates of 25 seeds. The following parameters were analyzed: germination percentage, germination speed index, first germination count and length and dry mass of seedlings. The temperature of $30^{\circ} \mathrm{C}$ and sand substrate are indicated for the conduction of the germination tests and vigor of the M. urundeuva seeds.
\end{abstract}

Keywords: Aroeira, Forest seeds, Medicine plant and Seed analysis.

\section{INTRODUÇÃO}

A aroeira-do-sertão (Myracrodruon urundeuva Allemão), pertencente à família Anacardiaceae, tem seu limite de distribuição natural que se estende pelas regiões Nordeste, Sudeste e Centro-Oeste do Brasil, até a região chaquenha da Bolívia, Paraguai e Argentina (CARVALHO, 1994; GURGEL-GARRIDO et al., 1997; LORENZI, 2002).
No Brasil, a espécie está presente em diversas formações vegetais, incluindo matas mesofíticas, sempre-verdes, subcaducifólias e caducifólias (RIBEIRO et al., 1983). Conforme Prado e Gibbs (1993), esta espécie é um importante componente da vegetação arbórea da caatinga, sendo característica e dominante, mas também se estende em direção à caatinga arbustiva.

\footnotetext{
${ }^{1}$ Recebido em 10.03.2009 e aceito para publicação em 02.05.2011.

${ }^{2}$ Programa de Pós-Graduação em Agronomia pela Universidade Federal da Paraíba, UFPB, Brasil. E-mail: <roberta_biologa09@yahoo.com.br>.

${ }^{3}$ Universidade Federal da Paraíba, Centro de Ciências Agrária, Departamento de Fitotecnia e Ciências Ambientais. E-mail: <ednaursulino@cca.ufpb.br>.

${ }^{4}$ Universidade Federal Rural de Pernambuco, UFRPE, Brasil. E-mail: <edilmapg@hotmail.com>e < jeandsonsv@hotmail.com>.

${ }^{5}$ Engenheiro Agrônomo pela Universidade Federal da Paraíba, Centro de Ciências Agrárias, Departamento de Fitotecnia e Ciências Ambientais. E-mail: <pnqc@msn.com.br>.

${ }^{6}$ Programa de Pós-Graduação em Engenharia Agrícola, Universidade Federal de Campina Grande, UFCG, Brasil. E-mail: <serrano1205@hotmail.com>.
} 
A M. urundeuva é uma espécie arbórea que se destaca nestas regiões por suas várias utilizações: arborização de ruas e praças, apicultura, curtimento de couro, pois suas cascas são ricas em tanino, medicina popular (tratamento de hemorragias, infecções respiratórias, urinárias e distúrbios no sistema digestório), tendo sido comprovados também efeitos antiinflamatórios e cicatrizantes (MATOS, 1999; ALBUQUERQUE et al., 2004). Tal como outras espécies com características nobres e elevado valor econômico, M. urundeuva tem sua exploração predatória, acarretando o comprometimento de suas populações naturais, requerendo estudos para garantir a sua conservação. Em decorrência dessa ampla utilidade e exploração, a espécie foi incluída na lista oficial do IBAMA como ameaçada de extinção, na categoria vulnerável (IBAMA, 2008).

As sementes constituem a via de propagação mais empregada na implantação de plantios, sendo de fundamental interesse o estudo de vários fatores que interferem na propagação, principalmente a germinação e o vigor, que influenciam de forma direta na distribuição das espécies. O substrato e a temperatura são dois importantes fatores que afetam o processo germinativo das sementes durante o teste de germinação. A influência na germinação das sementes pelos fatores ambientais, como temperatura e substrato, pode ser manipulada a fim de otimizar a percentagem, velocidade e uniformidade de germinação, resultando na obtenção de plântulas mais vigorosas e na redução de gastos de produção (NASSIF et al., 2009).

O substrato tem a função de suprir as sementes de umidade e proporcionar condições adequadas à germinação e ao posterior desenvolvimento das plântulas (FIGLIOLIA et al., 1993), influenciando diretamente a germinação, em função de sua estrutura, aeração, capacidade de retenção de água, grau de infestação de patógenos, dentre outros, podendo favorecer ou prejudicar a germinação das sementes (POPINIGIS, 1985).

A temperatura é outro fator que pode regular o processo germinativo, pois, de acordo com Carvalho e Nakagawa (2000), a temperatura afeta a percentagem, velocidade e uniformidade de germinação e está relacionada com os processos bioquímicos. Segundo Mayer e Poljakoff-Mayber (1989), há uma temperatura ótima na qual se verifica uma máxima percentagem e velocidade de germinação, acima e abaixo da qual a germinação é prejudicada. Sementes de muitas espécies expressam seu máximo potencial germinativo em temperaturas constantes, porém outras o fazem sob temperaturas alternadas (FIGLIOLIA et al., 1993).

Para sementes de Cnidosculus phyllacanthus Pax e K. Hoffm. Silva e Aguiar (2004) recomendaram os substratos areia, vermiculita, papel germitest e papel filtro combinados com a temperatura alternada de 20-30 C. Pacheco et al. (2006), trabalhando com a espécie Myracrodruon urundeuva Allemão, testaram diferentes substratos (entre e sobre: papel mata-borrão, areia, vermiculita e pó de coco) e temperaturas $(25,27,30$, $35,20-27,20-30$ e $20-35^{\circ} \mathrm{C}$ ) e observaram que as temperaturas de 25 e $27^{\circ} \mathrm{C}$ proporcionaram às sementes resultados satisfatórios de germinação em todos os substratos testados, com exceção do substrato entre papel a $27^{\circ} \mathrm{C}$ e, dentre os substratos, a vermiculita e o pó de coco é que permitiram bom desempenho germinativo. As temperaturas constantes de 25 e $30^{\circ} \mathrm{C}$, a temperatura alternada de $20-30{ }^{\circ} \mathrm{C}$ e os substratos pó de coco e areia foram as melhores condições para a germinação das sementes de Cedrela odorata L. (PASSOS et al., 2008). O substrato de papel-toalha na temperatura de $30^{\circ} \mathrm{C}$ foi o mais adequado para condução de testes de germinação e vigor em sementes de Cereus jamacaru DC. (GUEDES et al., 2009). Para sementes de Eucalyptus dunnii Maiden são indicados areia ou papel (CETNARSKI FILHO; CARVALHO, 2009). Os substratos areia e vermiculita foram os mais apropriados para avaliação da qualidade fisiológica das sementes de Amburana cearensis (Allemão) A.C. Smith (GUEDES et al., 2010).

Apesar de haver grande diversidade de espécies nativas no Brasil, poucas estão incluídas nas Regras para Análises de Sementes. Para as sementes de Myracrodruon urundeuva, ainda não estão estabelecidos os critérios para a realização do teste de germinação. Assim, o objetivo do trabalho foi avaliar substratos e temperaturas ideais para testes de germinação e vigor com sementes de $M$. urundeuva, visando à determinação de procedimentos adequados.

\section{MATERIAL E MÉTODOS}

O experimento foi realizado no Laboratório deAnálise de Sementes, do Centro de Ciências Agrárias, da Universidade Federal da Paraíba, em Areia - PB. As sementes de Myracrodruon urundeuva foram coletadas 
manualmente em 10 plantas matrizes que se encontravam em ambiente natural, no início do processo de deiscência dos frutos, em novembro de 2008, no município de Soledade - PB. Depois de colhidas, as sementes foram beneficiadas e mantidas em laboratório, à sombra, para secagem natural, por cinco dias. Em seguida, foram submetidas aos seguintes testes:

\subsection{Teste de germinação}

Para o teste de germinação, foram utilizadas quatro repetições de 25 sementes, sendo colocadas nos substratos papel-toalha, organizado na forma de rolo, entre e sobre papel mata-borrão, e entre os substratos vermiculita, areia, plantmax ${ }^{\circledR}$ e bioplant ${ }^{\circledR}$. Os substratos vermiculita e areia foram umedecidos com água destilada a $60 \%$ de sua capacidade de retenção de água, e as sementes foram semeadas a $1 \mathrm{~cm}$ de profundidade em caixas plásticas transparentes do tipo gerbox, com dimensões de 11 x 11 x $3 \mathrm{~cm}$. No substrato, o papeltoalha as sementes foram distribuídas sobre duas folhas, cobertas com uma terceira, e organizados em forma de rolo umedecido com água destilada no volume $(\mathrm{mL})$ equivalente a 2,5 vezes o peso do substrato, sem adição posterior de água. No substrato papel mata-borrão, as sementes foram distribuídas sobre o papel e, em relação ao substrato entre papel mata-borrão, foi posta uma folha de papel-toalha sobre as sementes. O umedecimento seguiu o mesmo padrão do papel-toalha. As avaliações foram efetuadas diariamente após a instalação do teste, por um período de 15 dias, quando se observou a formação de plântulas normais, ou seja, que continham a raiz primária e a parte aérea perfeitas, considerando como germinadas as plântulas com os cotilédones acima do substrato. Os resultados foram expressos em porcentagem.

\subsection{Primeira contagem de germinação}

Foi realizada conjuntamente com o teste de germinação, onde foram contadas as plântulas aos seis dias após o início do teste, sendo os dados expressos em percentagem.

\section{3. Índice de velocidade de germinação (IVG)}

O índice de velocidade de germinação foi avaliado conjuntamente com o teste de germinação. Foram realizadas contagens diárias, do $6^{\circ}$ até o $15^{\circ}$ dia após a semeadura, das sementes germinadas, e o índice de velocidade de germinação foi calculado empregando-se a fórmula proposta por Maguire (1962):IVG $=\frac{G_{1}}{N}+\frac{G_{2}}{N_{2}}+\ldots+\frac{G_{n}}{N_{\eta}}$, sendo $G_{1}, G_{2}$ e $G_{n}=$ número de plântulas normaís computadas na primeira, na segunda e na última contagem; $\mathrm{N}_{1}, \mathrm{~N}_{2}$ e $\mathrm{N}_{\mathrm{n}}=$ número de dias da semeadura na primeira, segunda e última contagem.

\subsection{Comprimento e massa seca de plântulas}

No final do teste de germinação, as plântulas normais de cada tratamento e repetição foram medidas (raiz e parte aérea), com auxílio de uma régua graduada em centímetros, sendo os resultados expressos em cm/plântula. As mesmas plântulas da avaliação anterior foram colocadas em sacos de papel Kraft e levadas à estufa a $65^{\circ} \mathrm{C}$, até atingir massa constante (48 horas). Decorrido esse período, foram pesadas em balança analítica com precisão de 0,001 g (NAKAGAWA, 1999).

\subsection{Delineamento experimental}

A análise de variância do experimento foi realizada segundo o delineamento experimental inteiramente ao acaso, com os tratamentos distribuídos em esquema fatorial $4 \times 7$ (4 temperaturas $\times 7$ substratos), com quatro repetições de 25 sementes cada. Os dados foram submetidos à análise de variância, e as médias foram comparadas pelo teste de Scott - Knott, a 5\% de probabilidade.

\section{RESULTADOS E DISCUSSÃO}

Na avaliação estatística dos dados, foi constatado efeito significativo para as interações dos substratos e temperaturas de todas as avaliações, à exceção do teste de germinação, dos substratos na temperatura de $30^{\circ} \mathrm{C}$. Na Tabela 1, encontram-se os dados referentes às médias da porcentagem de germinação de sementes de $M$. urundeuva, pelas quais se verificou que houve interações entre os diferentes substratos e temperaturas. As maiores porcentagens de germinação ocorreram na interação da temperatura de $20-30$ e $35^{\circ} \mathrm{C}$ com os substratos plantmax ${ }^{\circledR}$ e entre papel mata-borrão, bem como na temperatura de $30{ }^{\circ} \mathrm{C}$, independente do substrato utilizado.

Quando foram utilizados os substratos areia e vermiculita, sobre papel mata-borrão e papeltoalha, organizado em forma de rolo, na temperatura de $25{ }^{\circ} \mathrm{C}$, foram encontrados os menores percentuais de germinação, não ultrapassando os 60\%, verificando-se a necessidade de germinação em temperaturas mais elevadas, o que caracteriza as

Revista Árvore, Viçosa-MG, v.35, n.5, p.975-982, 2011 
Tabela 1 - Germinação (\%) de sementes de Myracrodruon urundeuva All. em diferentes substratos e temperaturas. Table 1 - Germination (\%) of Myracrodruon urundeuva All. seeds in different temperatures and substrates.

\begin{tabular}{|c|c|c|c|c|}
\hline \multirow[t]{2}{*}{ Substratos } & \multicolumn{4}{|c|}{ Temperaturas $\left({ }^{\circ} \mathrm{C}\right)$} \\
\hline & 25 & 30 & 35 & $20-30$ \\
\hline$\overline{\text { Areia }}$ & $44 \mathrm{cC}$ & 80 aA & $66 \mathrm{bB}$ & $66 \mathrm{bB}$ \\
\hline Vermiculita & $35 \mathrm{cC}$ & 73 aA & $62 \mathrm{bB}$ & $59 \mathrm{cB}$ \\
\hline Bioplant ${ }^{\circledR}$ & $51 \mathrm{bC}$ & 79 aA & $65 \mathrm{bB}$ & $70 \mathrm{bB}$ \\
\hline Plantmax ${ }^{\circledR}$ & $60 \mathrm{aB}$ & 76 aA & 77 aA & 81 aA \\
\hline Sobre papel mata-borrão & $37 \mathrm{cC}$ & 80 aA & $70 \mathrm{bB}$ & $68 \mathrm{bB}$ \\
\hline Entre papel mata-borrão & $40 \mathrm{cB}$ & 84 aA & $80 \mathrm{aA}$ & 76 aA \\
\hline Papel-toalha & $35 \mathrm{cC}$ & 76 aA & $48 \mathrm{cB}$ & $54 \mathrm{cB}$ \\
\hline CV $(\%)$ & 9,30 & & & \\
\hline
\end{tabular}

Médias seguidas de mesma letra minúscula na coluna e maiúscula na linha não diferem a 5\% pelo teste de Scott Knott. Means followed by the same lower case letter within column and capital letter within row do not differ at 5\% by Scott Knott test.

condições encontradas em seu hábitat natural. A interação significativa entre temperatura e substrato foi relatada por Figliolia et al. (1993), explicando que a capacidade de retenção de água e a quantidade de luz que o substrato permite chegar à semente podem ser responsáveis por diferentes respostas obtidas até para a mesma temperatura.

Em trabalho realizado com sementes de $M$. urundeuva procedentes de Serra Talhada - PE, também houve interação significativa entre temperatura e substrato, entretanto, nas combinações entre as temperaturas de 25 e $27^{\circ} \mathrm{C}$ e os substratos entre e sobre areia, vermiculita e pó de coco, houve elevadas porcentagens de germinação (PACHECO et al., 2006). Esses resultados indicam que a procedência pode exercer forte influência nas condições ideais de realização de testes de germinação e vigor de sementes.

Os resultados obtidos neste trabalho reforçam a afirmação de que o potencial germinativo máximo das sementes da maioria das espécies tropicais e subtropicais ocorre na faixa de temperatura entre 20 e $30^{\circ} \mathrm{C}$ (BORGES; RENA, 1993). No entanto, verificouse que as sementes de $M$. urundeuva também são capazes de extrapolar essa faixa, semelhante ao que ocorreu com sementes de Dinizia excelsa Ducke (VARELA et al., 2005) e Schizolobium amazonicum Huber ex Ducke (RAMOS et al., 2006).

Os dados referentes ao vigor, determinados pelo índice de velocidade de germinação, encontram-se na Tabela 2. Os maiores índices foram observados para as sementes de $M$. urundeuva submetidas às temperaturas de 30 e $35^{\circ} \mathrm{C}$, com o papel-toalha; e a 20-30 ${ }^{\circ} \mathrm{C}$ com o substrato entre papel mata-borrão. Assim, como se verificou para a porcentagem de germinação, também se constatou que, para o índice de velocidade de germinação, a temperatura de $25^{\circ} \mathrm{C}$ foi responsável pelos menores índices para todos os substratos. Em trabalho realizado com sementes da mesma espécie, Pacheco et al. (2006) obtiveram as maiores velocidades de germinação na temperatura de $27^{\circ} \mathrm{C}$ entre e sobre vermiculita, de $30{ }^{\circ} \mathrm{C}$ entre vermiculita e de $30^{\circ} \mathrm{C}$ e 20-27 ${ }^{\circ} \mathrm{C}$ entre e sobre papel.

Esta maior velocidade de germinação descrita, provavelmente se deve à melhor uniformidade de umedecimento do substrato, pois Marcos Filho et al. (1987) relataram que a uniformidade de umidade do substrato durante a condução do teste de germinação é um fator primordial. Carvalho e Nakagawa(2000) também mencionaram que a germinação será mais rápida e o processo mais eficiente se maior for a temperatura, até certo limite. Desse modo, foi observado que as temperaturas de 30,35 e $20-30{ }^{\circ} \mathrm{C}$ proporcionaram velocidade maior, demonstrando que o limite de temperatura, na qual a velocidade de germinação é prejudicada, está acima de $35^{\circ} \mathrm{C}$.

Os maiores porcentuais de plântulas obtidos na primeira contagem ocorreram na interação da temperatura de $20-30{ }^{\circ} \mathrm{C}$ com os substratos plantmax ${ }^{\circledR}$ e bioplant $^{\circledR}$ (Tabela 3). Avaliando-se o efeito das temperaturas em cada um dos substratos, observa-se que foram obtidos os maiores porcentuais quando as sementes foram postas para germinar no substrato areia, nas temperaturas de 25 e $30^{\circ} \mathrm{C}$; em vermiculita nas temperaturas de 30,35 e $20-30{ }^{\circ} \mathrm{C}$; nos substratos sobre e entre papel mataborrão e rolo de papel-toalha na temperatura de $30^{\circ} \mathrm{C}$. Em geral, dentro de cada substrato, a temperatura

Revista Árvore, Viçosa-MG, v.35, n.5, p.975-982, 2011 
Tabela 2 - Índice de velocidade de germinação (IVG) de sementes de Myracrodruon urundeuva All. em diferentes substratos e temperaturas.

Table 2 - Germination speed index (GSI) of Myracrodruon urundeuva All. seeds in different temperatures and substrates.

\begin{tabular}{lccrr}
\hline Substratos & \multicolumn{3}{c}{ Temperaturas $\left({ }^{\circ} \mathrm{C}\right)$} \\
\cline { 2 - 4 } & 25 & 30 & 35 & $20-30$ \\
\hline Areia & $1,72 \mathrm{aC}$ & $5,35 \mathrm{Ba}$ & $3,88 \mathrm{cB}$ & $\mathrm{cA}$ \\
Vermiculita & $1,28 \mathrm{aB}$ & $3,42 \mathrm{cA}$ & $2,67 \mathrm{dA}$ & $\mathrm{dA}$ \\
Bioplant $^{\circledR}$ & $1,97 \mathrm{aC}$ & $4,12 \mathrm{cA}$ & $3,22 \mathrm{~dB}$ & $4,72 \mathrm{cA}$ \\
Plantmax $^{\circledR}$ & $1,56 \mathrm{aD}$ & $2,71 \mathrm{dC}$ & $3,29 \mathrm{~dB}$ & $5,48 \mathrm{cA}$ \\
Sobre papel mata-borrão $_{\text {Entre papel mata-borrão }}^{1,07 \mathrm{aD}}$ & $4,69 \mathrm{bB}$ & $3,75 \mathrm{cC}$ & $\mathrm{bA}$ \\
Papel-toalha & $1,47 \mathrm{aC}$ & $5,11 \mathrm{bB}$ & $4,83 \mathrm{bB}$ & $\mathrm{aA}$ \\
CV (\%) & $1,40 \mathrm{aC}$ & $6,01 \mathrm{aA}$ & $5,67 \mathrm{aA}$ & $4,71 \mathrm{cB}$ \\
\hline
\end{tabular}

Médias seguidas de mesma letra minúscula na coluna e maiúscula na linha não diferem a 5\% pelo teste de Scott Knott.

Means followed by the same lower case letter within column and capital letter within row do not differ at 5\% by Scott Knott test.

Tabela 3 - Primeira contagem de germinação (\%) de Myracrodruon urundeuva All. em diferentes substratos e temperaturas. Table 3 - First germination count (\%) of Myracrodruon urundeuva All. seeds in different temperatures and substrates.

\begin{tabular}{|c|c|c|c|c|}
\hline \multirow[t]{2}{*}{$\overline{\text { Substrato }}$} & \multicolumn{4}{|c|}{ Temperatura $\left({ }^{\circ} \mathrm{C}\right)$} \\
\hline & 25 & 30 & 35 & $20-30$ \\
\hline Areia & $33 \mathrm{dA}$ & $73 \mathrm{bA}$ & $66 \mathrm{aB}$ & $58 \mathrm{bC}$ \\
\hline Vermiculita & $26 \mathrm{bB}$ & 51 сA & $50 \mathrm{bA}$ & $46 \mathrm{cA}$ \\
\hline Bioplant ${ }^{\circledR}$ & $32 \mathrm{aC}$ & $71 \mathrm{bA}$ & $50 \mathrm{bB}$ & 66 aA \\
\hline Plantmax ${ }^{\circledR}$ & $6 \mathrm{cD}$ & $32 \mathrm{dC}$ & $50 \mathrm{bB}$ & 65 aA \\
\hline Sobre papel mata-borrão & $4 \mathrm{cD}$ & $71 \mathrm{bA}$ & $51 \mathrm{bC}$ & $62 \mathrm{bB}$ \\
\hline Entre papel mata-borrão & $10 \mathrm{cD}$ & $80 \mathrm{cA}$ & $41 \mathrm{cC}$ & $66 \mathrm{aB}$ \\
\hline Papel-toalha & $27 \mathrm{dC}$ & $67 \mathrm{bA}$ & $54 \mathrm{bB}$ & $49 \mathrm{cB}$ \\
\hline CV (\%) & 8,69 & & & \\
\hline
\end{tabular}

Médias seguidas de mesma letra minúscula na coluna e maiúscula na linha não diferem a 5\% pelo teste de Scott Knott.

Means followed by the same lower case letter within column and capital letter within row do not differ at 5\% by Scott Knott test.

de $30{ }^{\circ} \mathrm{C}$ foi a que promoveu o maior porcentual de plântulas por ocasião da primeira contagem. Resultados diferentes foram obtidos por Pacheco et al. (2006) com sementes da mesma espécie, e as maiores porcentagens de germinação na primeira contagem ocorreram na temperatura de $27^{\circ} \mathrm{C}$ entre vermiculita, bem como a $30^{\circ} \mathrm{C}$ entre e sobre vermiculita.

Os resultados obtidos neste trabalho concordam com os obtidos por Andrade e Pereira (1994) com sementes de Cedrela odorata L. que recomendaram o substrato papel-toalha a $30^{\circ} \mathrm{C}$. Lima e Garcia (1996) observaram que o substrato de papel-toalha proporcionou os melhores percentuais na primeira contagem da germinação, independentemente da temperatura $\left(25,25-35\right.$ e $\left.35^{\circ} \mathrm{C}\right)$ utilizada.

Os maiores comprimentos de plântulas (Tabela 4) foram obtidos de sementes submetidas à temperatura de $25^{\circ} \mathrm{C}$ com o substrato bioplant ${ }^{\circledR}$; de $30^{\circ} \mathrm{C}$ com os substratos areia, vermiculita, bioplant ${ }^{\circledR}$; de $35^{\circ} \mathrm{C}$ com areia e plantmax ${ }^{\circledR}$ e de $20-30^{\circ} \mathrm{C}$ com o substrato bioplant ${ }^{\circledR}$. Nos substratos sobre e entre papel e rolo de papel-toalha, observou-se elevada porcentagem de germinação de sementes de $M$. urundeuva, no entanto o comprimento das plântulas foi reduzido, provavelmente devido à alta incidência de fungos. Pacheco et al. (2006) obtiveram maior comprimento do hipocótilo de plântulas da mesma espécie quando as sementes foram submetidas às temperaturas de 25,27 e $35^{\circ} \mathrm{C}$ no substrato entre pó de coco, a $25^{\circ} \mathrm{C}$ sobre pó de coco e a $30^{\circ} \mathrm{C}$ entre vermiculita. Para Phoenix roebelenii O’Brien., o maior comprimento de raiz ocorreu quando o substrato foi areia e vermiculita (IOSSI et al., 2003). As melhores combinações para o comprimento de plântulas de Adenanthera pavonina $\mathrm{L}$. foram temperaturas de $30^{\circ} \mathrm{C}$ nos substratos sobre e entre pó de coco e sobre vermiculita, bem como $35^{\circ} \mathrm{C}$ em todos os substratos, exceto areia (SOUZA et al., 2007).

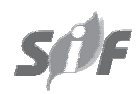

Revista Árvore, Viçosa-MG, v.35, n.5, p.975-982, 2011 
Tabela 4 - Comprimento de plântulas (cm) de Myracrodruon urundeuva All. em diferentes substratos e temperaturas. Table 4 - Length of Myracrodruon urundeuva All. seedlings in different temperatures and substrates.

\begin{tabular}{lcccc}
\hline Substratos & \multicolumn{3}{c}{ Temperaturas $\left({ }^{\circ} \mathrm{C}\right)$} \\
\cline { 2 - 5 } & 25 & 30 & 35 & $20-30$ \\
\hline Areia & $5,23 \mathrm{bC}$ & $7,79 \mathrm{aA}$ & $6,91 \mathrm{aB}$ \\
Vermiculita $^{\text {Bioplant }}{ }^{\circledR}$ & $5,15 \mathrm{bB}$ & $7,16 \mathrm{aA}$ & $6,54 \mathrm{bA}$ & $5,29 \mathrm{bB}$ \\
Plantmax $^{\circledR}$ & $6,53 \mathrm{aA}$ & $7,30 \mathrm{aA}$ & $7,12 \mathrm{bA}$ & $6,75 \mathrm{aA}$ \\
Sobre papel mata-borrão $_{\text {Entre papel mata-borrão }}^{4,99 \mathrm{bC}}$ & $6,03 \mathrm{bB}$ & $7,38 \mathrm{aA}$ & $6,44 \mathrm{aB}$ \\
Papel-toalha & $2,62 \mathrm{cB}$ & $3,96 \mathrm{cA}$ & $3,94 \mathrm{cA}$ & $\mathrm{cB}$ \\
CV (\%) & $3,07 \mathrm{cA}$ & $3,94 \mathrm{cA}$ & $3,33 \mathrm{cA}$ & $\mathrm{cA}$ \\
& $2,69 \mathrm{cA}$ & $0,00 \mathrm{~dB}$ & $0,00 \mathrm{~dB}$ & $0,00 \mathrm{~dB}$ \\
\hline
\end{tabular}

Médias seguidas de mesma letra minúscula na coluna e maiúscula na linha não diferem a 5\% pelo teste de Scott Knott. Means followed by the same lower case letter within column and capital letter within row do not differ at 5\% by Scott Knott test.

Tabela 5 - Massa seca de plântulas (g) de Myracrodruon urundeuva All. em diferentes substratos e temperaturas. Table 5 - Dry mass of Myracrodruon urundeuva All. seedling in different temperatures and substrates.

\begin{tabular}{lcccr}
\hline Substratos & \multicolumn{2}{c}{ Temperaturas $\left({ }^{\circ} \mathrm{C}\right)$} \\
\cline { 2 - 5 } & 25 & 30 & 35 & $20-30$ \\
\hline Areia & $0,06 \mathrm{bA}$ & $0,06 \mathrm{aA}$ & $0,04 \mathrm{aB}$ & $0,04 \mathrm{aB}$ \\
Vermiculita & $0,04 \mathrm{cA}$ & $0,03 \mathrm{cB}$ & $0,04 \mathrm{aB}$ & $0,02 \mathrm{bC}$ \\
Bioplant $^{\circledR}$ & $0,07 \mathrm{aA}$ & $0,04 \mathrm{bB}$ & $0,03 \mathrm{bB}$ & $0,03 \mathrm{aB}$ \\
Plantmax $^{\circledR}$ & $0,04 \mathrm{cA}$ & $0,03 \mathrm{bB}$ & $0,03 \mathrm{bB}$ & $0,02 \mathrm{bC}$ \\
Sobre papel mata-borrão $_{\text {Entre papel mata-borrão }}$ & $0,03 \mathrm{eA}$ & $0,03 \mathrm{bA}$ & $0,02 \mathrm{cB}$ & $0,02 \mathrm{bB}$ \\
Papel-toalha & $0,04 \mathrm{dA}$ & $0,03 \mathrm{bB}$ & $0,03 \mathrm{bA}$ & $0,02 \mathrm{bB}$ \\
CV (\%) & $0,01 \mathrm{fA}$ & $0,00 \mathrm{cB}$ & $0,00 \mathrm{~dB}$ & $0,00 \mathrm{cB}$ \\
Médias seguidas de mesma letra minúscula na coluna e maiúscula na linha não diferem a 5\% pelo teste de Scott Knott.
\end{tabular}

Means followed by the same lower case letter within column and capital letter within row do not differ at $5 \%$ by Scott Knott test.

O maior conteúdo de massa seca das plântulas de $M$. urundeuva foi encontrado apenas naquelas oriundas das sementes submetidas à temperatura de $25^{\circ} \mathrm{C}$ com o substrato bioplant ${ }^{\circledR}$ e na temperatura de $30{ }^{\circ} \mathrm{C}$ com o substrato areia (Tabela 5 ). O substrato areia também proporcionou maiores valores da massa seca da parte aérea e das raízes das plântulas de Mimosa caesalpiniifolia Benth. (SANTOS et al., 1994). Para Phoenix roebelenii O’Brien., Iossi et al. (2003) obtiveram maior conteúdo de massa seca das raízes quando utilizaram os substratos areia e vermiculita.

\section{CONCLUSÕES}

Por proporcionar alta germinação e produzir plântulas mais vigorosas, recomendam-se a temperatura de 30 ${ }^{\circ} \mathrm{C}$ e o substrato areia para a condução de testes de germinação e vigor de sementes Myracrodruon urundeuva.

\section{REFERÊNCIAS}

ALBUQUERQUE, R. J. M.; RODRIGUES, L. V.; VIANA, G. S. B. Análise clínica e morfológica da conjuntivite alérgica induzida por ovalbumina e tratada com chalcona em cobaias. Acta

Cirúrgica Brasileira, v.19, n.1, p.43-48, 2004.

ANDRADE, A. C. S.; PEREIRA, T. S. Efeito do substrato e da temperatura na germinação e no vigor de sementes de cedro - Cedrela odorata L. (Meliaceae). Revista Brasileira de Sementes, v.16, n.1, p.4-40, 1994.

BORGES, E. E. L.; RENA, A. B. Germinação de sementes. In: AGUIAR, I. B.; PIÑA-RODRIGUES, F. C. M.; FIGLIOLIA, M. B. Sementes

florestais tropicais. Brasília: ABRATES, 1993. p.83-135. 
CARVALHO, N. M.; NAKAGAWA, J. Sementes: ciência, tecnologia e produção. 4.ed. FUNEP: Jaboticabal, 2000. 588p.

CARVALHO, P. E. R. Espécies florestais brasileiras: recomendações silviculturais, potencialidades e uso da madeira. Brasília: Embrapa/CNPF, 1994. 640p.

CETNARSKI FILHO, R.; CARVALHO, R. I. N. Massa da amostra, substrato e temperatura para teste de germinação de sementes de Eucalyptus dunnii Maiden. Ciência Florestal, v.19, n.3, p.257-265, 2009.

FIGLIOLIA, M. B.; OLIVEIRA, E. C.; PIÑARODRIGUES, F. C. M. Análise de sementes. In: AGUIAR, I. B.; PIÑA-RODRIGUES, F. C. M.; FIGLIOLIA, M. B. (Coords.). Sementes florestais tropicais. Brasília: ABRATES, 1993. p.137-174.

GUEDES, R. S. et al. Germinação de sementes de Cereus jamacaru DC. em diferentes substratos e temperaturas. Acta Scientiarum. Biological Sciences, v.31, n.1, p.159-164, 2009.

GUEDES, R. S. et al. Substratos e temperaturas para testes de germinação e vigor de sementes de Amburana cearensis (Allemão) A.C. Smith. Revista Árvore, v.34, n.1, p.57-64, 2010.

GURGEL-GARRIDO, L. M. A. et al. Efeitos do sombreamento no crescimento da aroeira Myracrodruon urundeuva Fr. All. Revista do Instituto Florestal, v.9, n.1, p.47-56, 1997.

\section{INSTITUTO BRASILEIRO DE MEIO AMBIENTE E} DOS RECURSOS NATURAIS RENOVÁVEIS -

IBAMA. Lista oficial de espécies da flora brasileira ameaçada de extinção. Portaria ${ }^{\circ}$.37-N de 3 de abril de 1992. Disponível em: <http://www.ibama.gov.br>. Acesso em: dez. de 2008.

IOSSI, E. et al. Efeitos de substratos e temperaturas na germinação de sementes de tamareira-anã (Phoenix roebelenii O’Brien).

Revista Brasileira de Sementes, v.25, n.2, p.63-69, 2003.
LIMA, D.; GARCIA, L. C. Avaliação de métodos para o teste de germinação em sementes de Acacia mangium Willd. Revista Brasileira de Sementes, v.18, n.2, p.180-185, 1996.

LORENZI, H. Árvores Brasileiras: manual de identificação e cultivo de plantas arbóreas do Brasil. 2.ed. São Paulo: 2002. v.2. 384p.

MAGUIRE, J. D. Speed of germination aid in selection and evaluation for seedling emergence and vigor. Crop Science, v.2, n.2, p.176-177, 1962.

MARCOS FILHO, J.; CÍCERO, S. M.; SILVA, W. R. Avaliação da qualidade das sementes. Piracicaba: FEALQ, 1987. 230p.

MATOS, F. J. A. Plantas de medicina popular do Nordeste: propriedades atribuídas e confirmadas. Fortaleza: Edições UFC, 1999. 80p.

MAYER, A. C.; POLJAKOFF-MAYBER, A. The germination of seeds. London: Pergamon Press, 1989. 270p.

NAKAGAWA, J. Testes de vigor baseados na avaliação das plântulas. In: VIEIRA, R. D.; CARVALHO, N. M. Testes de vigor em sementes. Jaboticabal: FUNEP, 1999. Cap. 2. p.1-24.

NASSIF, S. M. L.; VIEIRA, I. G.; FERNANDES, G. D. Fatores externos (ambientais) que influenciam na germinação de sementes. Disponível em http://www.ipef.br/tecsementes/ germinacao.html> . Acesso em: 09 mar. 2009.

PACHECO, M. V. et al. Efeito de temperaturas e substratos na germinação de sementes de Myracrodruon urundeuva Fr. All. (Anacardiaceae). Revista Árvore, v.30, n.3, p.359-367, 2006.

PASSOS, M. A. A. et al. Luz, substrato e temperatura na germinação de sementes de cedrovermelho. Pesquisa Agropecuária Brasileira, v.43, n.2, p.281-284, 2008.

POPINIGIS, F. Fisiologia da semente. Brasília: AGIPLAN, 1985. 298p.

PRADO, D. E.; GIBBS, P. E. Patterns of species distributions in the dry seasonal forests of South America. Annals of the Missouri Botany Garden, v.80, p.902-927, 1993.

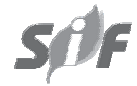

Revista Árvore, Viçosa-MG, v.35, n.5, p.975-982, 2011 
RAMOS, M. B. P.; VARELA, V. P.; MELO, M. F. F. Influência da temperatura e da água sobre a germinação de sementes de paricá (Schizolobium amazonicum Huber ex Ducke - Leguminosae Caesalpinoideae). Revista Brasileira de Sementes, v.28, n.1, p.163-168, 2006.

RIBEIRO, J. F. et al. Os principais tipos fitofisionômicos da região dos

Cerrados. Planaltina: Embrapa/CPAC, 1983. 28p. (Boletim de Pesquisa, 21)

SANTOS, D. S. B. et al. Efeito do substrato e profundidade de semeadura na emergência e desenvolvimento de plântulas de sabiá. Revista Brasileira de Sementes, v.16, n.1, p.50-53, 1994.
SILVA, L. M. M.; AGUIAR, I. B. Efeito dos substratos e temperaturas na germinação de sementes de Cnidosculus phyllacanthus Pax \& K. Hoffm. (faveleira). Revista Brasileira de Sementes, v.26, n.1, p.9-14, 2004.

SOUZA, E. B. et al. Germinação de sementes de Adenanthera pavonina L. em função de diferentes temperaturas e substratos. Revista Árvore, v.31, n.3, p.437-443, 2007.

VARELA, V. P.; RAMOS, M. B. P.; MELO, M. F. F. Umedecimento do substrato e temperatura na germinação de sementes de angelim-pedra (Dinizia excelsa Ducke). Revista Brasileira de Sementes, v.27, n.2, p.130-135, 2005. 